\title{
Rare Presentation of a Facial Giant Cell Tumor: A Case Report
}

\author{
Nádia AH Fortes*, Nema Walle, Yaima Perez, Brian René Januário and Bento Manhique \\ Maputo Central Hospital, Mozambique
}

\begin{abstract}
Giant Cell Tumors (GCT) are benign bone neoplasms, of mesenchymal nature, with uncertain biological behavior, uncommonly located in the craniofacial skeleton. These tumors have a high probability of recurrence after surgical treatment. We intend to report a case of GCT of grotesque dimensions located simultaneously in the mandible, jaws, right malar bone, palatal bones, and maxillary sinus walls, in an 18-year-old melanodermic male patient with 10-years evolution, that was observed at the Central Hospital of Maputo-Mozambique. In which a radical and oncological surgical treatment would be necessary considering the cure of the patient with the lowest possible toxicity in the short and long term, preserving the function and aesthetics of the patient, without excluding periodic postoperative follow-up. In conclusion, it is a challenge to approach this specific clinical case of a tumor with this type of presentation given Mozambique's unfavorable health care conditions.
\end{abstract}

ABBREVIATIONS: GCT: Giant Cell Tumors; CT: Computed Tomography; NMR: Nuclear Magnetic Resonance; FNAP: Fine Needle Aspiration Puncture; RT: Radio Therapy

\section{INTRODUCTION}

Giant cell tumors (GCT) are benign bone neoplasms, corresponding to $5 \%$ of primary bone neoplastic lesions. Although benign, these tumors are locally aggressively, with a high probability of recurrence after surgical treatment. In the craniofacial skeleton, its origin is uncommon, with reports in the parieto-occipital bones, maxilla, zygomatic, and in the laryngeal cartilages [1,2]. This article aims to report a case of GCT with extensive dimensions located simultaneously in the mandible, jaws, right malar bone, palatal bones, and maxillary sinus walls, therefore of rare location in these facial bones.

\section{LITERATURE REVIEW}

Giant Cell Tumor (GCT) or osteoclastoma is a benign bone neoplasm, of a locally aggressive mesenchymal nature, of uncertain biological behavior [3]. It consists histologically of multinucleated giant cells dispersed in tumor tissue, whose nucleus has the same characteristic of the very vascularized ovoid and fusiform cells that form its stroma [3-7]. Cooper and Travers in 1818, were the first to report bone lesions compatible with the GCT. Jaffe and Lichtenstein, in 1940, defined the aspects related to the histological, clinical and
2 radiographic aspect of this tumor, differentiating it from other types of bone neoplasms of the locomotor system [3,5]. GCT is one of the most common benign primary bone neoplasms, correspond 4 to $5 \%$ of primary bone tumors and $18.2-20 \%$ of benign bone tumors [3,5] and represent $8.6 \%$ of all malignant bone tumors [8], and is characterized by frequent recurrences and a limited ability to give distant metastases $[3,4,6]$, mainly pulmonary metastases in $2-3 \%$ of cases [2]. GCT is a neoplasm with malignant potential, especially when it affects males in advanced age, the primary form of malignancy is rare, often malignant transformations are secondary to radiotherapy in the form of sarcomatosis [9].

About $60 \%$ of these lesions occur at the articular end of long bones, such as the proximal tibia, distal femur, distal radius, and proximal humerus, preferably with metaphyseal, eccentric location, soon after epiphyseal closure. Spinal impairment is not common and constitutes $7 \%$ of all GCT. Most of these affect the sacrum, followed by the thoracic, cervical, and lumbar spine. Usually predominate in the vertebral body, with a frequent invasion of the posterior arch. The extension of this lesion to adjacent soft tissues is also frequent $[3,10,11]$.
Quick Response Code:

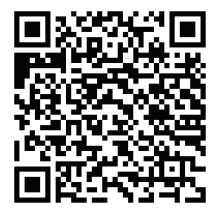

Address for correspondence: Nadia AH Fortes, Department of Surgery, OroMaxillofacial Surgery Service, Maputo Central Hospital, Maputo-Mozambique

Received: July 16, 2020 Published: September 1, 2020

How to cite this article: Nádia AHF, Nema W, Yaima P, Brian RJ, Bento M. Rare Presentation of a Facial Giant Cell Tumor: A Case Report. 2020 - 2(5) OAJBS.ID.000213. DOI: 10.38125/ OAJBS.000213 
When they occur in the cephalic segment, they are rare and are in the order of frequency in the mandible, in the upper jaw, skull base, and mandibular condyle [9]. Very infrequently they can also affect other structures such as zygomatic bone, external auditory canal, petrous pyramid, frontal bone, occipital bone, ethmoidal bone, sphenoid bone, sphenoid sinus, and jugular foramen [10]. When the GCT affects the bones of the facial massif, Pagett's disease is almost always associated [3,9]. Usually this lesion has a monostotic presentation, but occasionally may present in the polyostotic form in $1 \%$ of cases [2].

Regarding epidemiology, the TCG has an incidence of approximately 1 case per 1,000,000 inhabitants per year, with a greater prevalence in the eastern population, with a high prevalence in China (where it is more frequent in males) and South India (in the State of Andhra Pradesh) [12]. Being much less frequent in the black race than in the Caucasian race [9]. It has a peak incidence between 20 and 40 years old, with a slight predominance in females in a proportion of $(2: 1)$, with benign tumors being more frequent in females and malignant tumors in males $[11,12]$. The reported incidence in children under 10 years old is 3\%, affecting regions such as the mandible in about $7 \%,[2,4]$ there are few cases described over the age of 60 [9].

Regarding the origin, there are several theories about its etiopathogenesis: inflammatory, angiogenic and osteoclastic, but none of them is demonstrated. The role that the p53 suppressor gene plays in its genesis has recently been confirmed [9]. To classify the GCT, a grading system based on the radiographic aspect was developed by Campanacci there is no clinical correlation in this Table $1[6,9,13]$.

Table 1:

\begin{tabular}{|c|c|}
\hline Grade I & $\begin{array}{l}\text { Small or medium-sized tumor, does not expand the cortex, with well-defined margins, surrounded by } \\
\text { sclerosis and slow growth (intraosseous lesion) }\end{array}$ \\
\hline $\begin{array}{l}\text { Grade II (vast } \\
\text { majority } 70-80 \% \text { ) }\end{array}$ & $\begin{array}{l}\text { Medium or large tumor that expands the cortex without breaking it, margins not well defined without } \\
\text { sclerosis and fast growth (the periosteum is intact) }\end{array}$ \\
\hline Grade III & $\begin{array}{l}\text { Tumor of large size that breaks the cortex, margins not well defined. suggesting aggressiveness, it infiltrates } \\
\text { the soft tissues and of irregular fast growth, (aggressive but benign extra-bony lesion) }\end{array}$ \\
\hline
\end{tabular}

\section{It is also classified into three stages:}

stage 1: intraosseous lesion with histology and initial radiology.

stage 2: intraosseous lesion with expansion and thinning of the cortex, but with periosteum intact.

stage 3: extra osseous and aggressive lesion.

Stage 2 corresponds to 70 to $80 \%$ of the cases [2]. Other authors classify them as aggressive and non-aggressive. The aggressive form, which is more frequent, corresponds to large, fast-growing, painful, bleeding tumors with tooth mobility. There may be root reabsorption and perforation of the cortical bone. It presents a high rate of recurrence to curettage in 40-60\% [9]. The non-aggressive form corresponds to asymptomatic tumors, of smaller size and with much less recurrence to treatment [9].

The clinical presentation for head and neck injuries varies according to the location of the tumor, with volumetric increase in the topography of the lesion, deformity, pain of varying intensity, neurological deficits, salivation, tooth loss and pathological fractures $(11-37 \%)[2,3,7,9]$. The time of its progression is variable and depends on the bone and the affected region, but it refers to being slow, circumscribed, normally asymptomatic, with variable biological behavior [14].

The classic radiological aspects define it as a purely lytic lesion (areas of radiolucency), insufflative, eccentric, which promotes cortical tapering or erosion, that is, the appearance of the edges of the tumor may vary from a well-defined margin with little sclerosis around it, to the edges ill-defined with expansion and destruction of the cortex breaking it. Periosteal reaction is described in less than a third of cases $[2,4,13]$. Computed tomography (CT) scans allow detailing the behavior of the lesion, soft tissue affection, expansion or erosion of the cortex, bone destruction and extension of the lesion [14]. more clearly demonstrates pseudo trabeculations, absence of mineralizing matrix and eventual pathological fractures $[2,6]$. Bone scintigraphy shows broad concentration of the radio indicator in the lesion, as central photopenia, it is called "donut sign" $[2,4,6]$

Nuclear Magnetic Resonance (NMR) can be useful in assessing the extension of the tumor to soft tissues, being superior to computed tomography. Cystic areas inside the lesion are also frequently characterized by NMR, which may be due to hemorrhages or the formation of secondary aneurysmal bone cysts $[2,3,6]$. The diagnosis must be based on clinical, radiographic and histological data, sometimes complementary studies with laboratory tests, although not specific, since multinucleated giant cells are rich in acid phosphatase, hence the search for serum calcium, phosphorus and PHT is necessary to differentiate from the tumor. hyperparathyroidism and to know associated diseases such as Pagett's disease $[9,12]$. Studies using Fine Needle Aspiration Puncture (FNAP) demonstrate the existence of receptors for calcitonin in the cytoplasm of multinucleated giant cells [9]. Differential diagnoses include benign tumors rich in giant cells such as aneurysmal bone cyst, central reparative giant cell granuloma, peripheral giant cell granuloma, cherubism, brown giant cell tumor, brown tumor of hyperparathyroidism $[2,9,14]$.

Differential diagnosis can also be made with similar radiological entities such as odontogenic myxoma, osteoblastoma, chondroblastoma and ameloblastoma. Other lesions to consider are the foreign body reaction, vascular lesions, and malignant lesions above all osteosarcoma and, much less frequently, the Langerhans cell histiocytoma and leukemia [9]. The preferred treatment is surgical. That it is necessary in most cases due to the possibility of metastatic disease due to several risk factors [13]. The options include curettage of the lesion combined with cauterization of the margins and / or use of liquid nitrogen, it has been shown to be a reliable method, associated or not with methods of filling the bone defect such as bone cement or bone graft; local resection of the lesion, marginal or with wide margins, or "en bloc" resections for more extensive lesions, which may require reconstruction methods $[2,6,9]$. 
These methods may include primary synthesis of the mucosal defect, skin grafts to cover bone exposure, and use of free flaps with microsurgical anastomosis. The submental flap is gaining popularity for its simple technique in the reconstruction of small to moderate defects of the oral cavity, with an inconspicuous scar in the donor area, good arc of rotation, axial blood supply, proximity to the oral cavity, in addition to providing different thicknesses [3]. A limitation of its use would be in males, because of the growth of beards in that region, which can be mitigated by the epithelialization of the flap [2], this also indicated total excision of the tumor and replacement by endoprosthesis or autologous bone tissue $[6,10]$.

Benign GCT's are highly prone to local recurrence. $81 \%$ of recurrences after surgery, appear in the first 2 years. The malignant transformation was recorded either after treatment only with radiotherapy or only with surgery $[10,12]$. The main objective of radical treatment is to bring about the cure of the patient with the lowest possible toxicity in the short and long term while preserving function, 1 always recommending follow-up by means of periodic controls [9]. Large size lesions and aggressive behavior can be used with adjuvant therapies to reduce the size and the risk of tumor bleeding during surgery. Among them, pre-surgical embolization, intra-lesional injection of corticosteroids, and systemic administration of calcitonin stand out. It is stated that with the daily subcutaneous injection of interferon alfa-2a, it is possible to lead to complete tumor regressions, as well as bone filling of the residual cavities [9]. Radiotherapy (RT) in the treatment of these tumors is uncertain, due to the potential risk of inducing sarcomas. RT has been used by most institutions as a palliative measure in patients with local recurrences or distant metastases. With current surgical techniques employed, low recurrence rates have been achieved, therefore being one of the reasons for not using RT $[7,9]$.

It is advisable to use RT in patients who with surgery would cause an important iatrogeny in places with difficult surgical approach, being important the careful evaluation of each case in a multidisciplinary forum (oncologists, radiotherapists, traumatologists, radiologists, surgeons, etc.) [1]. Regarding the prognosis, the histological type and degree of expression of the p53 suppressor gene must be considered, which is present in $20 \%$ of GCT cases, associated with pulmonary recurrence and metastasis $[2,9]$.

\section{CASE REPORT}

18-year-old male melanodermic patient, resident in Inhambane (Vilankulos-Mozambique) who attended Oral and Maxillofacial surgery medical consultations at Maputo Central Hospital, with a history of evolution of about 10 years of progressive increase in volume in the oral cavity and face, denies pain, headache and history of bleeding. He has no medical priors such as Tuberculosis, Diabetes Mellitus, and tested negative for HIV.

On physical examination of the face, facial asymmetry is observed at the expense of a stony hard mass in the mandible and upper left jaw, painless, skin with areas of hypopigmentation (Figure 1). The rest of the body segments without apparent and clinical changes.

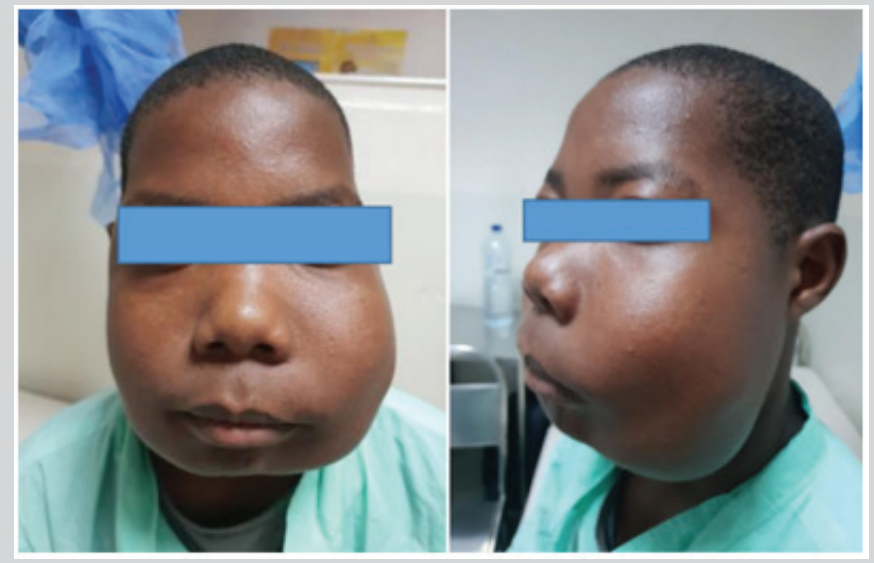

Figure 1: Giant cell tumor is seen in the frontal and profile views.
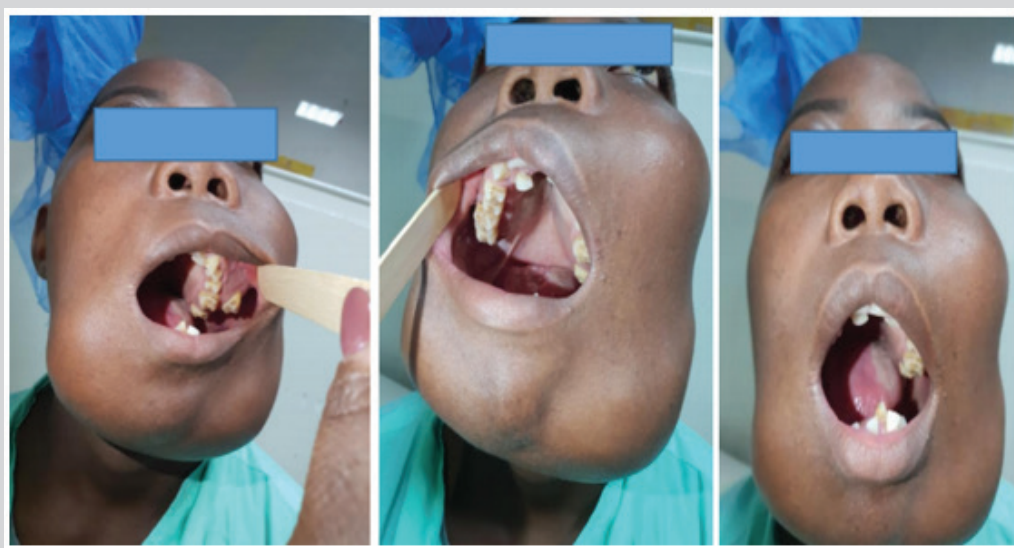

Figure 2: Intraoral view of giant cell tumor. 
In the oral cavity, there is central bone swelling of hard stony consistency with expansion of the buccal and lingual / palatine corticals, respectively, along the entire mandible and in the upper jaws, with affection of the left hard palate; displacement, crowding and tooth loss are observed causing poor dental occlusion (Figure 2 ). The oral mucosa is normal, and the gingival mucosa has no signs of inflammation and bleeding (Figure 2). Blood sample and chest radiography without changes, radiography of long bones without changes.

Cranioencephalic computed tomography (CT) scan without contrast revealed the presence of a giant bone neo-formative process involving the mandible and posterior wall of the maxillary sinus bilaterally, where the replacement of the bone component by soft tissue density tissue is observed, giving a lacy appearance and reducing infiltrated bone. Thus, the volume of the maxillary sinuses and an increase in volume of the lower portion of the face, reaching a 8 thickness of $5 \mathrm{~cm} \times 10 \mathrm{~cm} \times 1.3 \mathrm{~cm}$, extending from the posterior wall of the maxillary sinus to the mentonian region (Figure 3).

An incisional biopsy was performed under local anesthesia whose histological result was compatible with that of a Giant Cell Tumor (GCT), (Figure 4).
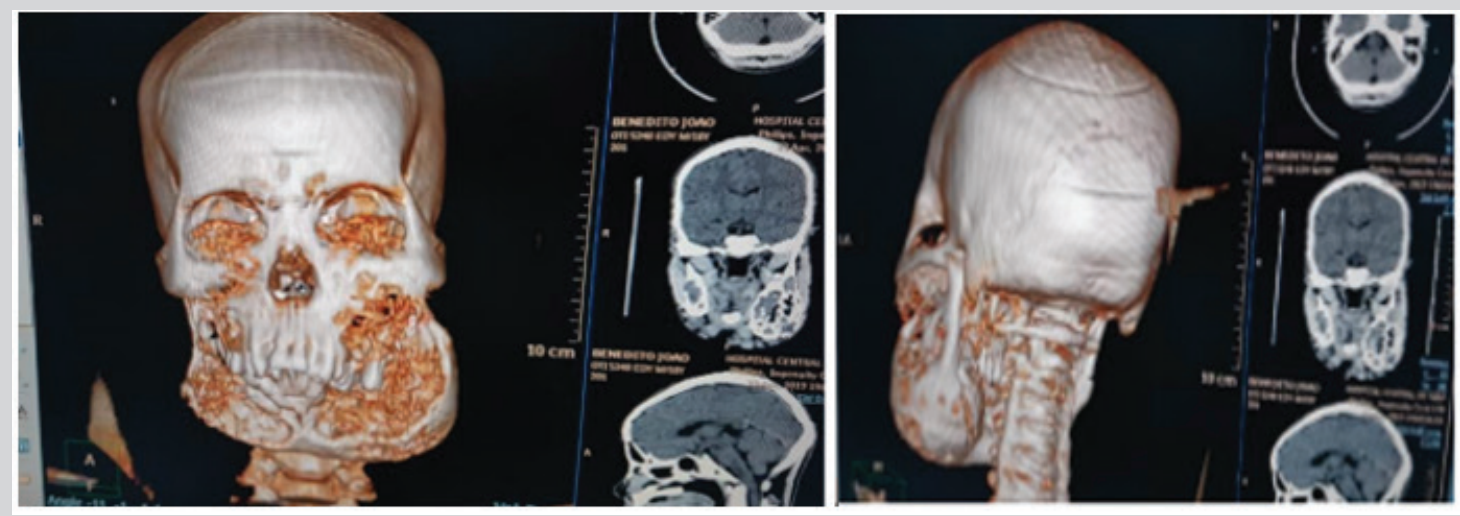

Figure 3: Radiographic images.

Figure 4: Fragment of soft tissue infiltrat

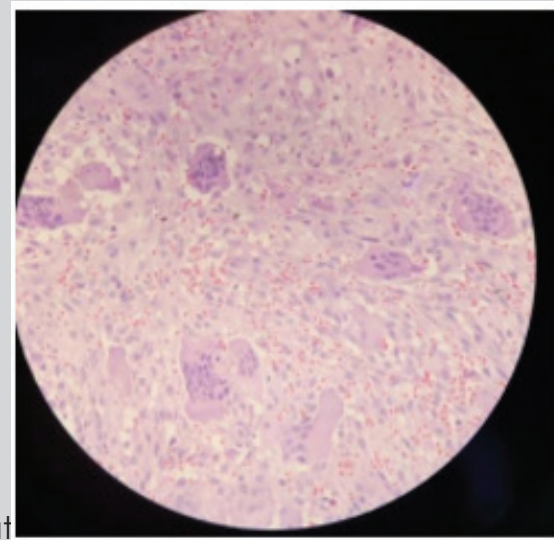

with slight atypia and low mitotic index. No necrosis is observed.

undles of multinucleated giant cells

\section{DISCUSSION}

A rare, benign lesion in the gnathic and facial bones, with a 10 year progression story in a young male who lived normally because his vital functions were preserved, with no complaint, or local pain, and his only discomfort was his deformed aesthetic appearance, which at some point in his life he thought it was normal. After clinical, radiographic, and histological examination, it was confirmed that it was a GCT, a benign bone neoplasia that corresponds to $5 \%$ of primary bone neoplastic lesions. Although benign, they may have a locally aggressive behavior originating in the craniofacial skeleton infrequently [2].

It was found that this GCT in the gnathic and facial bones was of a polyostotic nature, grade II, although of grotesque dimensions, analytically, associated Pagett's disease was discarded.
In the Campanacci classification, they constitute the vast majority, corresponding to about $70-80 \%$ of cases $[6,9,13]$. Usually, in its radiographic clinical presentation, a volumetric increase in the affected topographic region, deformity, tooth loss and pathological fractures are observed (11-37\%). The evolution time is variable, it depends on the bone and the affected region, however it refers to be of slow growth, circumscribed, normally asymptomatic that present a variable biological behavior $[2,3,7,9,14]$.

CT scan revealed the presence of giant bone neo-formative processes involving the mandible and posterior wall of the maxillary sinus was observed bilaterally, which includes the jaws themselves. Expansion, erosion of the cortex or bone destruction and extension of the lesion is 9 confirmed. And according to the literature consulted, the CT scan more clearly shows pseudo trabeculations, absence of a mineralizing matrix and possible 
pathological fractures $[2,6]$. Regarding the treatment, it should be borne in mind that this lesion is not confined to only one facial bone and with a very specific location, as commonly the lesion presents when it occurs in the mandibula. In this specific case the lesion occupies topographically the entire mandibula, both jaws, palatine bones, and maxillary sinuses, which because of the high rates of local recurrence although GCT is benign, it would be indicated as total tumor excision treatment and replacement by endoprosthesis $[6,10]$. Although the literature describes that $81 \%$ of recurrences after the surgery arise in the first two years $[10,12]$.

A mandibulectomy and right and left maxillectomy would be viable surgical techniques, however, the challenge would be to think of a reconstructive treatment in which the patient would continue with his preserved functions, but there's also the fact that he is inserted in a country where the socio-economic reality is not favorable in regards to subsequent health care treatments. Radiotherapy, even if palliative, should be careful not to predispose the malignant transformation into sarcomas, given the patient's age, the size of the lesion and the affected sex. And it must also be considered that it is a rare pathology entity in the bones of the face, in a country like Mozambique where health care would be expensive and the adjuvant treatment, radiotherapy considered controversial. The main objective of radical treatment is to bring about the cure of the patient with the lowest possible toxicity in the short and long term while preserving function $[1,7]$, always recommending followup using periodic controls $[9,15,16]$.

\section{CONCLUSION}

The GCT is a benign neoplasm, locally aggressive, rare in the gnathic and facial bones. The treatment is mostly surgical assisted by radiotherapy in specific cases. In polyostotic presentations of the gnathic bones and face, radical treatment must be instituted preserving the function or at least established in the perspective of the possibility of a post-surgical reconstruction. Periodic checks are mandatory due to the high recurrence rates.

\section{REFERENCES}

1. González DME, González SSYMC, Muñoz FDL (2009) Papel de la radioterapia en tumores óseos benignos de células gigante. Revista
Española de Enfermedades Metabólicas Óseas 18(4): 65-69.

2. Gilberto MMJ, Marco AVK, José DSB, Hélio RNA, Eber MM (2015) Ressecção de tumor de células gigantes da mandíbula e reconstrução com retalho submentoniano Rev Bras Cir Cabeça Pescoço 44(1): 32-34.

3. Garza NJM, Ceccopieri CA, Cruz OH, Díaz RLR, Martínez MR (1999) Tumor de células gigantes de hueso. Aspectos generales de 11 casos. Rev Med Hosp Gen Mex 62(4): 240-244.

4. Cristiano S, Deíse SG, Marcelle AB, Gislaine CLM, Rubens C (2009) Tumor de células gigantes de mandíbula. Rev Assoc Med Bras 55(2): 108-9108.

5. Marco AGBF (2012) Tumor de células gigantes em adolescentes-revisão de literatura. Salvador (Bahia), Universidade Federal da Bahia Faculdade de Medicina Da Bahia p: 1-21.

6. Julian C, Alexandre CDF, Joel RBL, Alex DDO, Elisa SDM, et al. (2006) Tumor de celulas gigantes osseo: aspectos clinicos e radiograficos de 115 casos. Radiol Bras 39(2): 119-122.

7. Pedro PRB, José DDP, Eduardo SY (2001) Tumor de células gigantes. Rev Bras Ortop 36(7).

8. Carmen XR, Carlos U, Héctor S, Federico FP (2002) Tumor de células gigantes del primer metacarpiano Control a un año de su tratamiento quirúrgico. Rev Asoc Arg Ortop y Traumatol 67(4): 263-265.

9. Gomez OG, Garcia RGA, Lopez C JL (2005) Tumor de celulas gigantes mandibular. Rev Esp Cirug Oral y Maxilofac 27(6).

10. João PM, Julieta SM, Luiz AMS, Lizando FDCN, Cristina SM, et al. (2013) Tumor de células gigantes do seio frontal: relato de caso. Radiol Bras 46(4): 255-258.

11. Jerónimo M, Nicolás MC, Ignacio B, Leonor EYED (2011) Tumor de células gigantes en columna. Rev Hosp Ital B Aires 31(2): 60-62.

12. Cármen PC, Isabel S, Helena C, Tomé F (1998) Tumor De Celulas Gigantes Do Osso. Acta Médica Portucues 11: 563-568.

13. Aguilar EA, López SJ, Lillo AM, Peguero BA (2015) Treatment of giant cell tumors. Revista Cubana de Ortopedia y Traumatología 29(1): 1-7.

14. Sebastián K, María SB, Liset EODC, Carlos MV, PLF, et al. (2016) Tumor central de células gigantes en mandíbula: reporte de un caso clínico: Revista ADM 73(3): 144-150.

15. Cristiano S, Deíse SG, Marcelle AB, Gislaine CLM, Rubens C (2009) Tumor de celulas gigantes de mandibula. Rev Assoc Med Bras 55(2): 108-9108.

16. Alfonso AM, Loreto VMC (2003) Tumor mandibular de células gigantes. Rev Chilena de Cirugía 55(3): 270-273. 